\title{
Synthesis and Antimicrobial Studies of Tridentate Schiff Base Ligands with Pyrazolone Moiety and Their Metal Complexes
}

\author{
Ramasamy Jayarajan, Gnanasambandam Vasuki, and Pillutla Sambasiva Rao \\ Department of Chemistry, Pondicherry University, Puducherry 605 014, India \\ Correspondence should be addressed to Gnanasambandam Vasuki, vasukig@gmail.com
}

Received 8 September 2010; Revised 23 October 2010; Accepted 2 November 2010

Academic Editor: Feihe Huang

Copyright ( $) 2010$ Ramasamy Jayarajan et al. This is an open access article distributed under the Creative Commons Attribution License, which permits unrestricted use, distribution, and reproduction in any medium, provided the original work is properly cited.

Synthesis, characterization, and antimicrobial activity of tridentate Schiffbase ligands containing pyrazolone moiety (3a and $\mathbf{3 b}$ ) and their transition metal complexes of $\mathrm{VO}(\mathrm{II}), \mathrm{Cu}(\mathrm{II}), \mathrm{Fe}(\mathrm{III})$, and $\mathrm{Co}(\mathrm{II}) \mathbf{4} \mathbf{a}-\mathbf{h}$ have been investigated. The complexes show enhanced antibacterial activity against $S$. aureus, E. coli, and S. typhi and antifungal activity against C. albicans, Rhizopus sp., and A. niger compared to the ligands.

\section{Introduction}

Developing metal-based drugs is emerging as an active area of research. Many organic ligands particularly tridentate Schiff base ligands show enhanced antibacterial, antifungal, and carcinostatic activity when complexed to transition metal ions [1-7]. Heterocyclic systems bearing the pyrazolyl moiety show antibacterial, antifungal, anti-inflammatory and enzyme-inhibitory activity [8-11]. 4-acylpyrazolones are good chelating ligands. Synthesis and characterization of metal complexes of 4-acylpyrazoles are well documented [12-14]. However, biological activity of tridentate Schiff base ligands containing pyrazolone moiety and their transition metal complexes is not explored. Therefore, in the present paper we report the synthesis, characterization, and antimicrobial activity of tridentate Schiff bases of the type ONN (3a) and ONO (3b) containing the pyrazolone moiety and their $\mathrm{VO}(\mathrm{II}), \mathrm{Cu}(\mathrm{II}), \mathrm{Fe}(\mathrm{III})$, and $\mathrm{Co}(\mathrm{II})$ complexes.

\section{Results and Discussion}

3-Methyl-1-phenylpyrazol-5-one (1) and 4-acetyl-3-methyl1-phenylpyrazol-5-one were prepared by following the literatures procedure. 4-acetyl-3-methyl-1-phenylpyrazol-5-ones mainly exists as the 3-methyl-1-phenyl-4-acetylpyrazolin-5-ol tautomer (2). Condensing (2) with 1,2-diaminobenzene, and 2-aminophenol resulted in ONN-and ONO-type tridentate ligands (3a and $\mathbf{3} \mathbf{b}$ ), respectively. Ligands $\mathbf{3} \mathbf{a}$ and 3b were complexed with metal salts viz vanadyl sulphate monohydrate, copper(II) nitrate trihydrate, ferric chloride hexahydrate, and cobalt(II) nitrate hexahydrate to obtain, their corresponding complexes $(\mathbf{4} \mathbf{a}-\mathbf{h})$. Compounds $3 \mathbf{a}$ and 3 b were characterized by IR, ${ }^{1} \mathrm{H} \mathrm{NMR},{ }^{13} \mathrm{C} \mathrm{NMR}$, and elemental analysis. In addition to these spectral techniques LC-MS was also used for characterization of $3 a .{ }^{13} \mathrm{C} N M R$ and LC-MS data $(\mathrm{m} / \mathrm{e} 307)$ of $3 \mathbf{a}$ indicates the formation of tridentate ligand resulting from condensation of 2 with one amino group of 1,2-diaminobenzene. Though there is a possibility for biscondensation repeated experiments resulted in tridentate ligand (3a) only. Complexes $(\mathbf{4 a}-\mathbf{h})$ were characterized by IR, UV-Visible, mass, and EPR spectral studies. However, from the data available the structure of complexes could not be fully characterized. The proposed structures of the complexes are given in Table 1 . The coordination of methanol in $\mathrm{VO}$ (II) complexes (4a and $4 \mathbf{e}$ ) was verified by thermal analysis. Thermogram of complexes showed a weight loss around $70-130^{\circ} \mathrm{C}$ ascribable to loss of methanol in the complexes. Further conclusive evidence of the coordination of methanol in these complexes was 
shown by the appearance of $v(\mathrm{OH})$ around $3400 \mathrm{~cm}^{-1}$ in IR spectra.

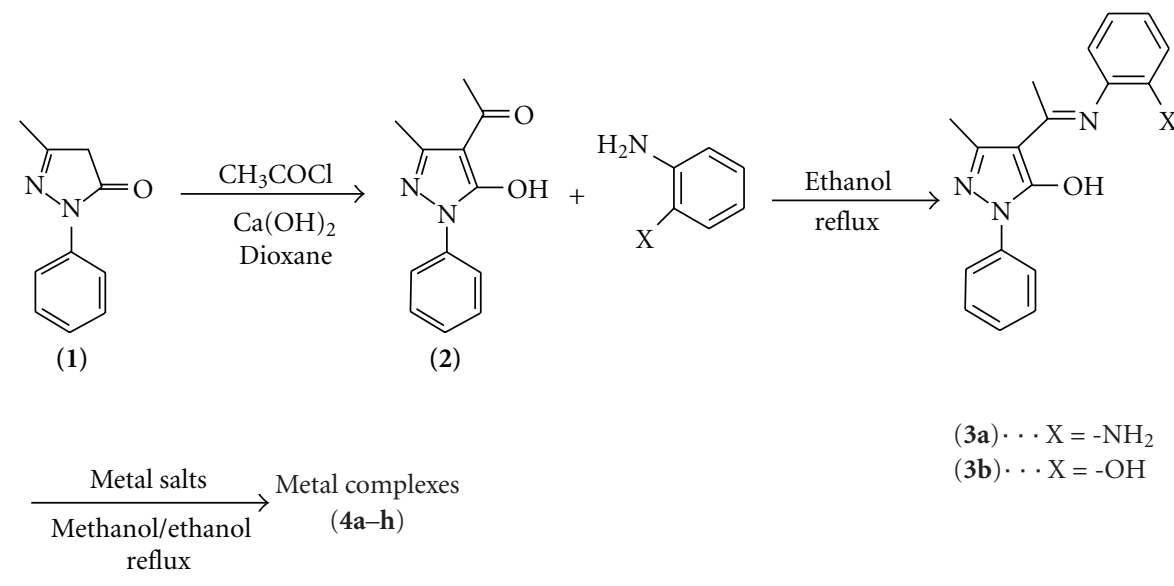

2.1. Antibacterial Studies. The ligands (3a-b) and complexes $(4 \mathbf{a}-\mathbf{h})$ synthesized were screened for their antibacterial activity by disc-diffusion method $[15,16]$ against Staphylococcus aureus (Gram positive), Pseudomonas aeruginosa (Gram negative), and Salmonella typhi (Gram negative). The test compounds were prepared at a concentration of $200 \mu \mathrm{g} / \mathrm{mL}$. Solvent control that is, DMSO was also maintained throughout the experiment simultaneously. Nutrient agar plates were prepared under sterile conditions and incubated overnight to detect contamination. About $0.2 \mathrm{~mL}$ of working stock culture was transferred into separate nutrient agar plates and spread thoroughly using a glass spreader. Whatman No. 1 discs (6 mm in diameter) were impregnated in the test compounds and dissolved in DMSO $(200 \mu \mathrm{g} / \mathrm{mL})$ for about half an hour. Commercially available drug disc (Ciprofloxacin $10 \mu \mathrm{g} /$ disc) was used as positive reference standard. Negative controls were also prepared by impregnating disc of same size in DMSO solvent. The discs were placed on the inoculated agar plates and incubated at $37 \pm 1{ }^{\circ} \mathrm{C}$ for about $18-24 \mathrm{~h}$. Antibacterial activity was evaluated by measuring the zone of inhibition $(\mathrm{mm})$ against the test organism Figure 1.

It is observed that, in general, metal complexes show enhanced antibacterial activity than the corresponding ligands. No general trend in the activity of the ligands or the metal complexes against the bacterial strain is observed. Iron complex 4c showed enhanced activity against all bacterial strains. 4c also showed very low minimum inhibitory concentration (MIC) value $(12.5 \mu \mathrm{g} / \mathrm{mL})$ of $S$. aureus. The activity of iron complex $\mathbf{4 g}$ is less compared to $\mathbf{4 c}$ for all bacterial strains.

Among the cobalt complexes $\mathbf{4 d}$ and $\mathbf{4 h}, \mathbf{4 h}$ is more effective against $S$. typhi with low MIC value $(25 \mu \mathrm{g} / \mathrm{mL})$ compared to the standard ciprofloxacin $(50 \mu \mathrm{g} / \mathrm{mL})$ as well as its corresponding iron complex.

2.2. Antifungal Studies. The antifungal activity of $\mathbf{3 a - b}$ and their complexes $(\mathbf{4} \mathbf{a}-\mathbf{h})$ were examined with three fungal strains namely Candida albicans, Rhizopus sp., and
Aspergillus niger. Drug amphotericin B was used as standard. Sabouraud's dextrose agar (SDA) medium was used for the growth of fungi, and testing was done in Sabouraud's dextrose broth (SDB) medium. The subculture and the viable count were carried out by the same procedure as done in antibacterial studies except the temperature was maintained at $28 \pm 1^{\circ} \mathrm{C}$ for about $72 \mathrm{~h}$. Similarly for disc diffusion method, the petri dishes were incubated at $28 \pm 1^{\circ} \mathrm{C}$ for about $72 \mathrm{~h}$. The diameters of zone of inhibition ( $\mathrm{mm}$ ) of all the compounds are given in Figure 2.

It is observed that the diameter of zone of inhibition ( $\mathrm{mm}$ ) of cobalt complex $4 \mathrm{~h}$ shows very high activity with very low MIC value $(12.5 \mu \mathrm{g} / \mathrm{mL})$ against the fungal strain A. niger (MIC of standard amphotericin B is $50 \mu \mathrm{g} / \mathrm{mL}$ ).

\section{Conclusions}

4-Acetylpyrazolone predominantly exists as 3-methyl-1phenyl-4-acetylpyrazolin-5-ol tautomer. The 3-methyl-1phenyl-4-acetylpyrazolin-5-ol readily condenses with 1,2diaminobenzene and 2-aminophenol forming tridentate Schiff base ligands of ONN and ONO type. The metal complexes of these ligands with $\mathrm{VO}(\mathrm{II}), \mathrm{Cu}(\mathrm{II}), \mathrm{Fe}(\mathrm{III})$, and $\mathrm{Co}$ (II) show varying geometries. The ligands and metal complexes exhibit varying degree of antibacterial and antifungal activity. In general $\mathrm{Fe}$ (III) and $\mathrm{Co}(\mathrm{II})$ complexes are more potent than other complexes and ligands.

\section{Experimental Section}

4.1. General Procedures. ${ }^{1} \mathrm{H}$ NMR and ${ }^{13} \mathrm{C}$ NMR spectra were recorded on a Bruker 400 instrument using tetramethylsilane (TMS) as internal standard and $\mathrm{CDCl}_{3}$, or $\mathrm{DMSO}-\mathrm{d}_{6}$ as solvent. Chemical shifts are given in parts per million (ppm). IR spectra were recorded on a Nicolet 6700 FT-IR Spectrophotometer in $\mathrm{KBr}$ pellet method in the range of $400-4000 \mathrm{~cm}^{-1}$. UV-Vis spectra were obtained from Ocean Optics HR 4000 Spectrophotometer and using DMF as a solvent in a $1 \mathrm{~cm}$ quartz cell. Elemental analyses were carried 
TABLE 1: Proposed structure of complexes.

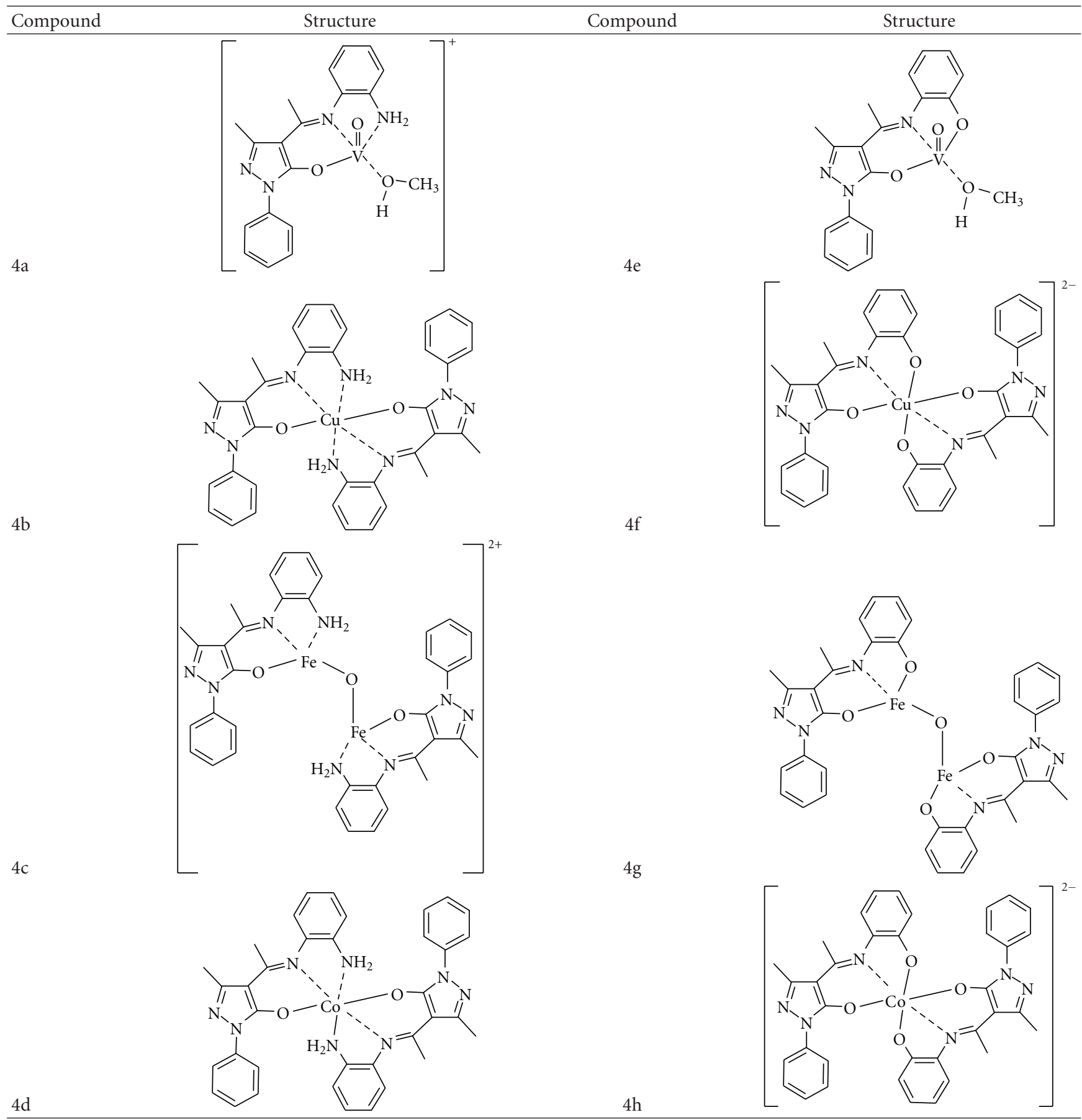

out on a Perkin-Elmer 2400 Series CHNS/O analyzer. The ESI-mass spectra were recorded in QTOF-Micromass-UK by using DMF as solvent, and the LC-MS was taken in Shimadzu LC-MS using acetonitrile as solvent. Thermogravimetric analyses were recorded on TA Instruments Q 600 SDT. The EPR spectra of complexes were recorded in JEOL JES-TE 100 EPR Spectrometer operating at X-band frequency.
3-Methyl-1-phenylpyrazoline-5-one (1). 3-Methyl-1-phenylpyrazoline-5-one was prepared by following the literatures procedure [17].

3-Methyl-1-phenyl-4-acetylpyrazoline-5-ol (2). 3-Methyl-1phenyl-4-acetylpyrazoline-5-ol was prepared by following the literatures procedure [18]. 


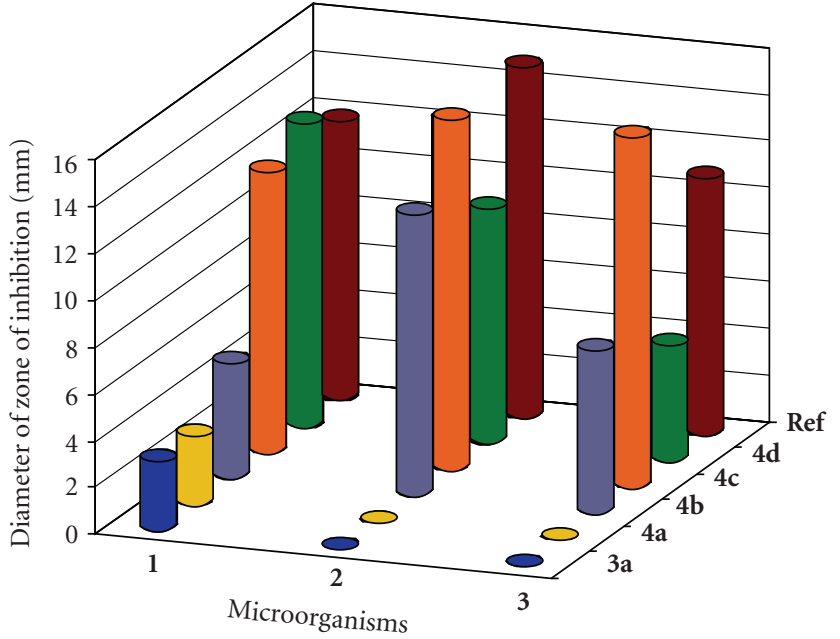

1: S. aureus

2: E. coli

3: S. typhi

Ref: Ciprofloxacin

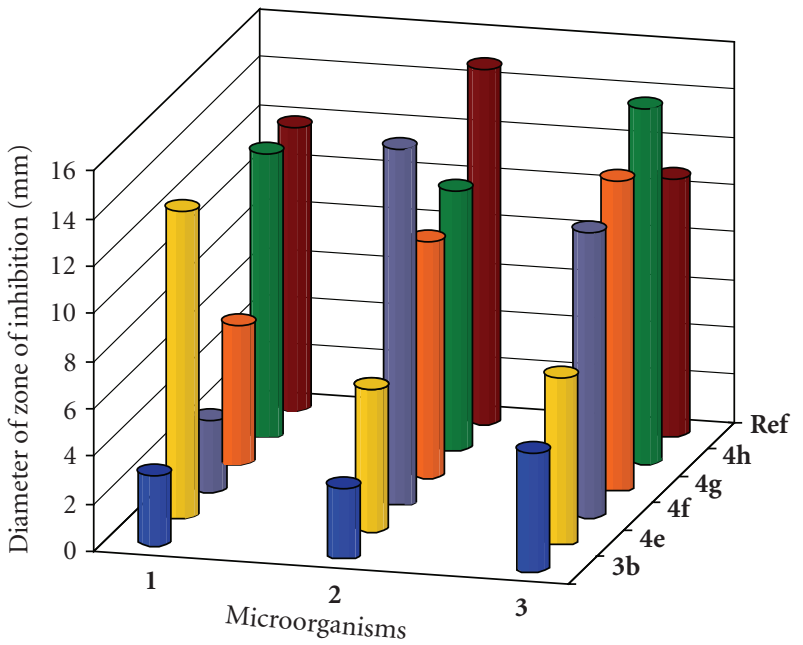

1: S. aureus

2: E. coli

3: S. typhi

Ref: Ciprofloxacin

(a)

(b)

Figure 1: Antibacterial activity of (3a-b) and (4a-h).

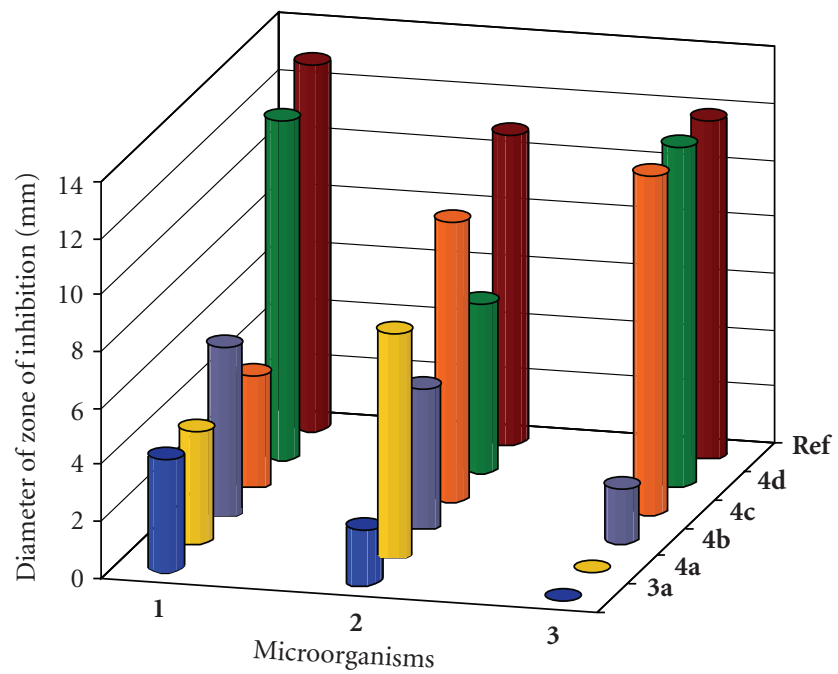

1: C. albicans

2: Rhizopus sp.

3: A. niger

Ref: Amphotericin B

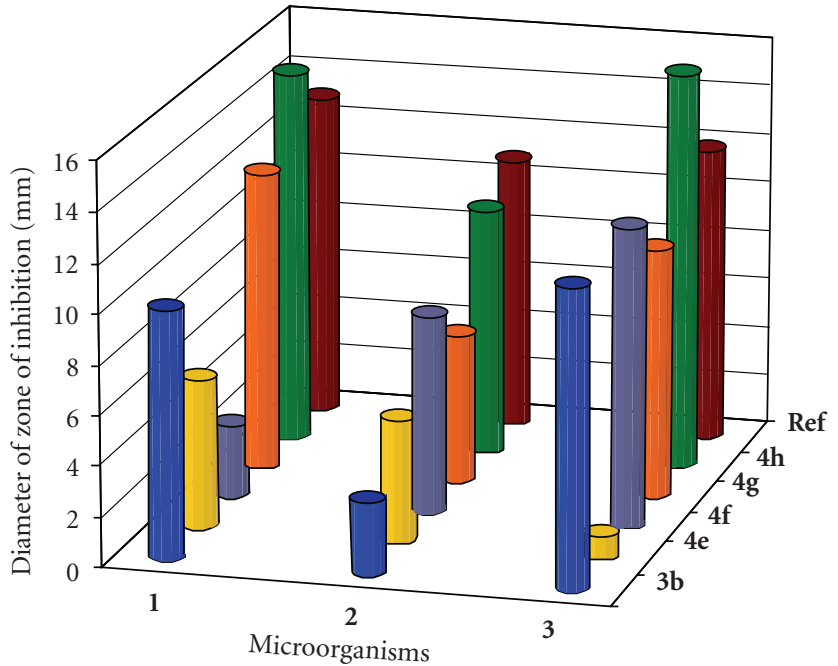

1: C. albicans

2: Rhizopus sp.

3: A. niger

Ref: Amphotericin B

(a)

(b)

Figure 2: Antifungal activity of (3a-b) and (4a-h).

4.2. General Procedure for the Synthesis of Tridentate Schiff Base Ligands $(3 a-b)$. Ethanolic solution of 3-methyl-1phenyl-4-acetylpyrazolin-5-ol ( $2 \mathrm{mmoL})$ and 1,2-diaminobenzene $(2 \mathrm{mmoL})$ was taken in a round-bottom flask and refluxed for $3 \mathrm{~h}$. The solid product was filtered, washed with cold ethanol and recrystallized from ethanol, and dried under vacuum. A similar procedure was adopted for the reaction between 3-methyl-1-phenyl-4-acetylpyrazolin-5-ol
$(2 \mathrm{mmoL})$ and 2 -aminophenol $(2 \mathrm{mmoL})$ to synthesize $\mathbf{3 b}$, but the reaction mixture was refluxed for $8 \mathrm{~h}$ and the product was recrystallized from acetonitrile.

4-(1-(2-aminophenylimino) ethyl)-3-methyl-1-phenylpyrazol5-ol (3a). Yellow. Yield (75\%); m.p. $192^{\circ} \mathrm{C}$; IR $\left(\mathrm{KBr}, \mathrm{cm}^{-1}\right)$ : 3437 (OH stretch), 3350 (NH stretch), 3036 (aromatic $\mathrm{CH}$ stretch), 1621 (azomethine $\mathrm{C}=\mathrm{N}$ stretch), 1538 (cyclic 
TABLE 2: FT-IR and UV-Vis spectral data of complexes (3a-b and $\mathbf{4 a}-\mathbf{h})$.

\begin{tabular}{lccccc}
\hline \multirow{2}{*}{ S No. } & Code & C=N & IR $(\mathrm{KBr}) \mathrm{cm}^{-1}$ & $\mathrm{M}-\mathrm{L}$ & $\lambda \max (\mathrm{nm})$ \\
\hline 1 & 3a & 1621 & 1393 & - & 331,282 \\
2 & $4 \mathrm{a}$ & 1601 & 1383 & 511,478 & 413,261 \\
3 & $4 \mathrm{~b}$ & 1609 & 1384 & 507,435 & $617,399,298$ \\
4 & $4 \mathrm{c}$ & 1600 & 1382 & 501,453 & 415,285 \\
5 & $4 \mathrm{~d}$ & 1594 & 1383 & 514,460 & $331,364,291$ \\
6 & 3b & 1623 & 1388 & - & 315 \\
7 & $4 \mathrm{e}$ & 1636 & 1355 & 513,455 & $601,399,294$ \\
8 & $4 \mathrm{f}$ & 1597 & 1377 & 511,482 & 442,291 \\
9 & $4 \mathrm{~g}$ & 1600 & 1382 & 507,455 & $541,376,301$ \\
10 & $4 \mathrm{~h}$ & 1593 & 1369 & 511,461 & \\
\hline
\end{tabular}

$\mathrm{C}=\mathrm{N}$ stretch $)$ and $1393(\mathrm{C}-\mathrm{O}$ stretch $),{ }^{1} \mathrm{H}$ NMR $\left(\mathrm{CDCl}_{3}\right)$ ppm: $\delta 2.29\left(\mathrm{~s}, 3 \mathrm{H}, \mathrm{CH}_{3}\right), 2.42\left(\mathrm{~s}, 3 \mathrm{H}, \mathrm{CH}_{3}\right), 3.9(\mathrm{~s}, 2 \mathrm{H}$, $\left.\mathrm{NH}_{2}\right), 6.77-8.02(\mathrm{~m}, 9 \mathrm{H}, \mathrm{CH}$ aromatic), and $12.58(\mathrm{~s}, 1 \mathrm{H}$, $\mathrm{OH}) ;{ }^{13} \mathrm{C}$ NMR $\left(\mathrm{CDCl}_{3}\right)$ ppm: $\delta 16.6,17.5,100.54,116.31$, $118.66,119.32,122.17,124.44,127.68,128.75,129.32$, 138.97, 142.6, 147.36, 165.56, and 165.85; LC-MS m/z 307 $[\mathrm{M}+\mathrm{H}]^{+}$; analytical calculation for $\mathrm{C}_{18} \mathrm{H}_{18} \mathrm{~N}_{4} \mathrm{O}: \mathrm{C}, 70.57 ; \mathrm{H}$, 5.92; and N, 18.29 found $\mathrm{C}, 70.52 ; \mathrm{H}, 5.86$; and $\mathrm{N}, 18.20$.

4-(1-(2-hydroxyphenylimino) ethyl)-3-methyl-1-phenylpyrazol5-ol (3b). Pale yellow. Yield (70\%); m.p. $220^{\circ} \mathrm{C}$; IR (KBr, $\mathrm{cm}^{-1}$ ): $\sim 3163$ ( OH stretch), 2982 (aromatic CH stretch), 1623 (azomethine $\mathrm{C}=\mathrm{N}$ stretch), 1532 (cyclic $\mathrm{C}=\mathrm{N}$ stretch) and 1388 (C-O stretch), ${ }^{1} \mathrm{H}$ NMR (DMSO- $\left.\mathrm{d}_{6}\right)$ ppm; $\delta 2.37\left(\mathrm{~s}, 3 \mathrm{H}, \mathrm{CH}_{3}\right), 2.38\left(\mathrm{~s}, 3 \mathrm{H}, \mathrm{CH}_{3}\right), 6.82-8.03(\mathrm{~m}, 9 \mathrm{H}$, $\mathrm{CH}$ aromatic), and $10.0(\mathrm{~s}, 1 \mathrm{H}$, phenolic $\mathrm{OH}) ;{ }^{13} \mathrm{C}$ NMR (DMSO-d ${ }_{6}$ ) ppm: $\delta 21.75,22.38,104.75,121.63,123.15$, $124.11,128.31,128.86,131.75,133.30,133.43,144.50$, $151.81,157.17,169.18$, and 170.43; analytical calculation for $\mathrm{C}_{18} \mathrm{H}_{17} \mathrm{~N}_{3} \mathrm{O}_{2}$ : C, 70.34; $\mathrm{H}, 5.58$; and N, 13.67 found $\mathrm{C}$, 70.27; $\mathrm{H}, 5.55$; and $\mathrm{N}, 13.58$.

4.3. General Procedure for the preparation of $\mathrm{VO}(\mathrm{II}), \mathrm{Cu}(\mathrm{II})$, $\mathrm{Fe}(I I I)$, and $\mathrm{Co}(I I)$ complexes $(4 a-h)$. The solution of Schiff base ligand $3 \mathbf{a} / \mathbf{3 b}(10 \mathrm{mmoL})$ in ethanol/methanol and metal salts $(10 \mathrm{mmoL})$ (vanadyl sulphate monohydrate $(1.8 \mathrm{~g})$, copper(II) nitrate trihydrate $(2.41 \mathrm{~g})$, cobalt(II) nitrate hexahydrate $(2.91 \mathrm{~g})$, and ferric chloride hexahydrate $(2.7 \mathrm{~g})$ in minimum quantity of ethanol/methanol were heated separately and mixed. The resultant solution was refluxed for 5-6h. The solution was then concentrated to half of its volume, filtered and washed several times with hot water and finally with hot alcohol. The product was dried under vacuum and recrystallized from DMF. All the metal complexes have a melting point above $250^{\circ} \mathrm{C}$.

4.4. IR Spectra. The FT-IR (KBr) spectra of all complexes $(4 \mathbf{a}-\mathbf{h})$ were recorded, and values are given in Table 2 . The IR of the Schiff base (3a) exhibits strong bands at $\sim 3350 \mathrm{~cm}^{-1}$ due to the presence of $\nu\left(\mathrm{NH}_{2}\right)$ varies in the complexes (4a-d) shows the coordination of amine group with metal ions. The band at $1621 \mathrm{~cm}^{-1}$ due to $\nu(\mathrm{C}=\mathrm{N})$ (azomethine) group is shifted to lower values indicating that the ligands are coordinated to the metal ions through the nitrogen of the azomethine group. Moreover, the presence of $\nu(\mathrm{C}=\mathrm{N})$ stretching in $\mathbf{3 b}$ also varies in the complexes compared to the ligand indicating the formation of the complexes. The band at 1300-1400 assignable to pyrazolone $v(\mathrm{C}-\mathrm{O})$ stretching in ligand varies in complexes. Further conclusive evidence of the coordination of these Schiff base ligands (3a-b) with metals was shown by the appearance of weak low-frequency new bands at $400-530 \mathrm{~cm}^{-1}$ corresponding to $\nu(\mathrm{M}-\mathrm{N})$ and $v(\mathrm{M}-\mathrm{O})$ stretching modes.

4.5. UV-Visible Spectra. The electronic spectra (Table 2) of the Schiff base ligands (3a-b) show absorption bands around $200-350 \mathrm{~nm}$ due to $\pi-\pi^{*}$ and $\mathrm{n}-\pi^{*}$ transitions for the benzene ring and azomethine group. In the spectra of the complexes, the absorption band of the azomethine chromophore $n-\pi^{*}$ transition is shifted compared to the ligand indicating that the imine nitrogen is involved in the coordination with metal ions. The spectra of the metal complexes $(\mathbf{4 a}-\mathbf{h})$ shows that the absorption around $400-$ $800 \mathrm{~nm}$ is due to ligand to metal charge transfer and d-d transition band of the metal in the complexes.

4.6. EPR Spectra. The powder and solution state EPR spectra for $4 \mathrm{a}, \mathbf{4 b}, \mathbf{4 c}, \mathbf{4 e}, \mathbf{4 f}$, and $\mathbf{4 g}$ have been recorded at Xband frequencies at room temperature and also in $77 \mathrm{~K}$ (LNT), and a typical spectra are shown in Figure 3. The calculated $g$ and hyperfine (A) values are given in Table 3. As expected, the $\mathrm{Co}(\mathrm{II})$ complexes (4d and $\mathbf{4 h}$ ) do not give rise to any EPR spectra down to $77 \mathrm{~K}$ due to relaxations, but formation of the complex was confirmed by mass spectra $(\mathrm{m} / \mathrm{z} 669)$, and an octahedral structure has been proposed.

The EPR spectrum of complexes $4 \mathrm{a}$ and $4 \mathbf{e}$ indicates that the paramagnetic ion responsible is $\mathrm{VO}(\mathrm{II})$ having $\mathrm{S}=1 / 2$ and $I=7 / 2$. A close look at the spectrum indicates a shoulder on hyperfine lines suggesting that the symmetry of the complex is lower than distorted octahedron. This is not a common observation, as the deviation from axial symmetry is not reported in powder spectrum. The room temperature 
TABLe 3: $g$ and A values for complexes. A values are in units of mT.

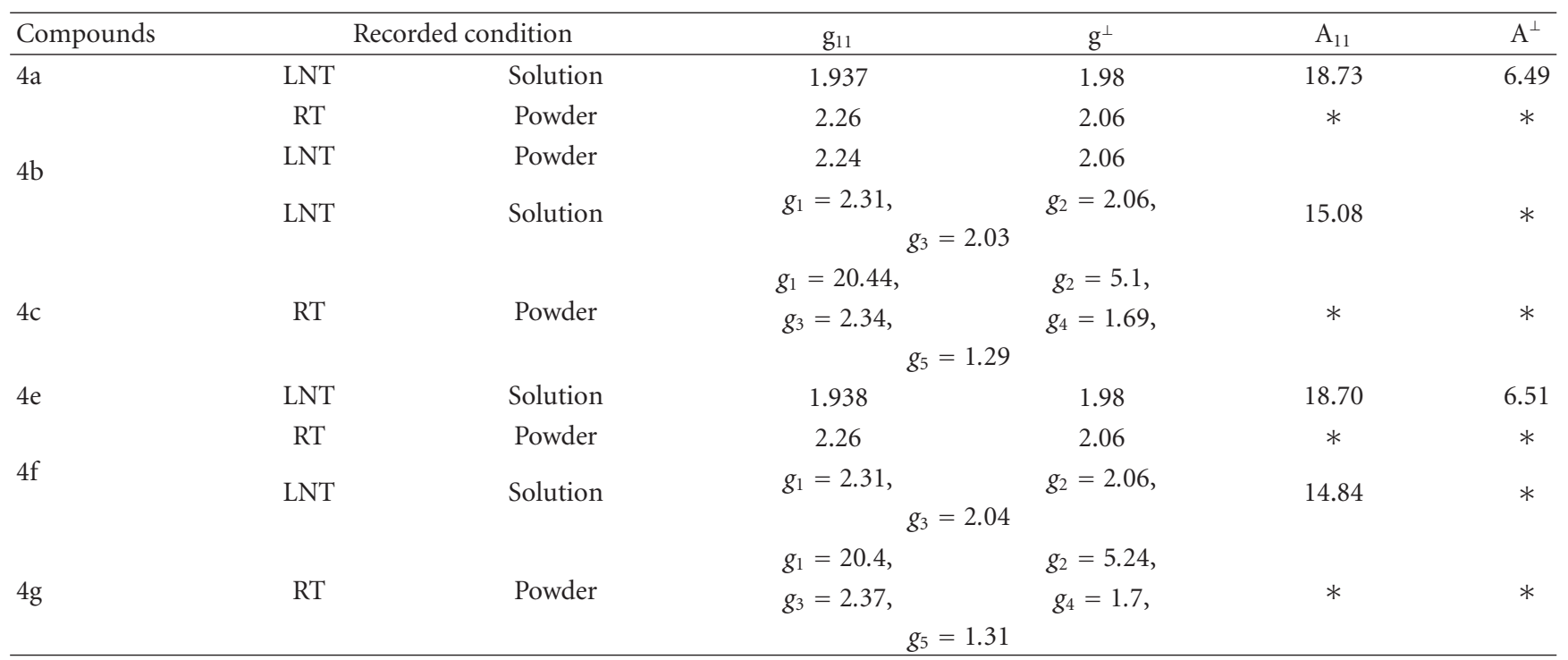

* unresolved.

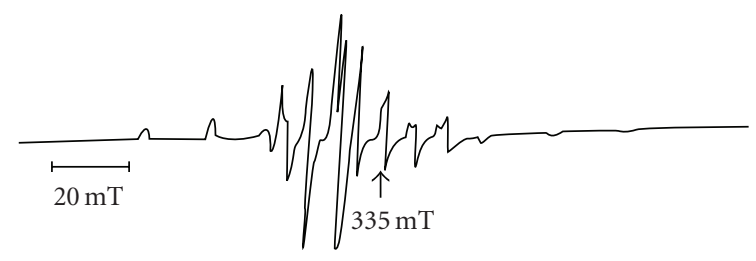

(a) EPR spectrum of 4 a solution at LNT (Freq $=9.06597 \mathrm{GHz}$ )

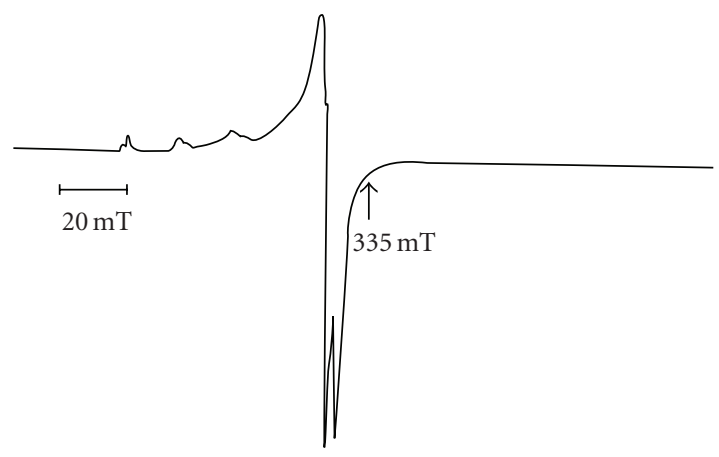

(b) EPR spectrum of $\mathbf{4 b}$ solution at LNT (Freq $=9.06786 \mathrm{GHz})$

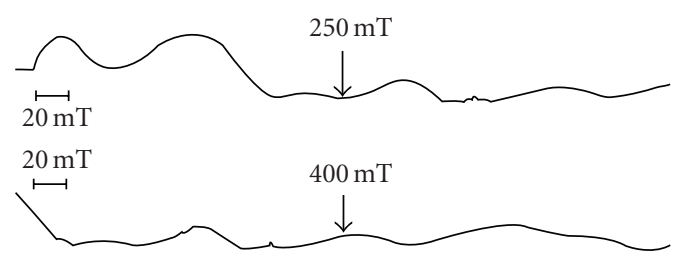

(c) EPR spectrum of $\mathbf{4 c}$ powder at RT $($ Freq $=9.38540 \mathrm{GHz})$

Figure 3

powder spectrum of $4 \mathrm{e}$ was also recorded. The calculated $\mathrm{g}$ and $\mathrm{A}$ values of $\mathbf{4 e}$ matched with the values of $\mathbf{4 a}$. This suggests that the coordination around vanadyl ion is nearly the same in both $\mathbf{4 a}$ and $4 \mathbf{e}$ except for a slight change in distortion [19].

Powder EPR spectrum of $\mathbf{4 b}$ was recorded at room temperature and $77 \mathrm{~K}$. The hyperfine lines from copper nucleus are not resolved at room temperature spectrum due to dipole-dipole broadening. In order to obtain the hyperfine values, the complex was dissolved in DMF, and EPR spectrum was recorded at $77 \mathrm{~K}$. The spectrum clearly indicates resonances from copper nucleus $\left({ }^{63} \mathrm{Cu} /{ }^{65} \mathrm{Cu}\right)$. The symmetry around the copper is lower than distorted octahedral as reflected from the three $g$ values [20]. Also the three g values suggest that the coordination around the copper is six, which was confirmed by mass spectra ( $\mathrm{m} / \mathrm{z} 665)$.

The powder EPR spectrum of $4 \mathrm{c}$ at room temperature shows a number of resonances indicating that iron is under the influence of a strong tetragonal distortion. The range of g-values suggests that all the three Kramers' doublets are populated at room temperature. The ESI-Mass of $4 \mathrm{c}$ complex $(\mathrm{m} / \mathrm{z} 740)$ suggests that the complex is oxygen bridged bimetallic iron complex. Moreover oxobridged iron complexes are well known in many literatures [21]. The recorded solution EPR spectrum shows a single resonance at $\mathrm{g}=2$. This kind of observation suggests that the dimeric iron complex might have become monomer after dissolution, hence a single line is observed [22]. The complex $\mathbf{4 g}$ behaves similar to $4 c$.

\section{Acknowledgments}

G.Vasuki. thanks the University Grants Commission and Department of Science and Technology (DST) for financial support. R.Jayarajan. thanks the UGC, New Delhi, India for the award of Rajiv Gandhi National Fellowship. 


\section{References}

[1] Z. H. Chohan and S. Kausar, "Synthesis, characterization and biological properties of tridentate NNO, NNS and NNN donor thiazole-derived furanyl, thiophenyl and pyrrolyl Schiff bases and their $\mathrm{Co}(\mathrm{II}), \mathrm{Cu}(\mathrm{II}), \mathrm{Ni}(\mathrm{II})$ and $\mathrm{Zn}(\mathrm{II})$ metal chelates," Metal-Based Drugs, vol. 7, no. 1, pp. 17-22, 2000.

[2] Z. H. Chohan, A. Rauf, and C. T. Supuran, "Antibacterial $\mathrm{Co}(\mathrm{II})$ and $\mathrm{Ni}$ (II) complexes of $\mathrm{N}$-(2-Furylmethyene)-2aminothiazole and role of $\mathrm{SO}_{4}^{2-}, \mathrm{NO}_{3}^{-}, \mathrm{C}_{2} \mathrm{O}_{4}^{2-}$ and $\mathrm{CH}_{3} \mathrm{CO}_{2}$ anions on biological properties," Metal-Based Drugs, vol. 8, no. 5, pp. 287-291, 2002.

[3] Z. H. Chohan, M. F. Jaffery, and C. T. Supuran, "Antibacterial $\mathrm{Co}(\mathrm{II}), \mathrm{Cu}(\mathrm{II}), \mathrm{Ni}(\mathrm{II})$ and $\mathrm{Zn}(\mathrm{II})$ complexes of thiadiazoles Schiff bases," Metal-Based Drugs, vol. 8, no. 2, pp. 95-101, 2001.

[4] Z. H. Chohan, A. Munawar, and C. T. Supuran, "Transition metal ion complexes of Schiff-bases. Synthesis, characterization and antibacterial properties," Metal-Based Drugs, vol. 8, no. 3, pp. 137-143, 2001.

[5] K. M. Patel, K. N. Patel, N. H. Patel, and M. N. Patel, "Synthesis, characterization, and antimicrobial activities of some transition metal complexes with a tridentate dibasic Schiff base and bidentate 2,2'-bipyridylamine," Synthesis and Reactivity in Inorganic and Metal-Organic Chemistry, vol. 31, no. 2, pp. 239-246, 2001.

[6] K. M. Patel, K. N. Patel, N. H. Patel, and M. N. Patel, "Synthesis, characterization and antimicrobial activities of some transition metal complexes with the schiff base of 5-bromosalicylaldehyde and o-aminophenol and 2,2'bipyridylamine," Synthesis and Reactivity in Inorganic and Metal-Organic Chemistry, vol. 30, no. 10, pp. 1965-1973, 2000.

[7] A. P. Mishra, M. Khare, and S. K. Gautam, "Synthesis, physicochemical characterization, and antibacterial studies of some bioactive Schiff bases and their metal chelates," Synthesis and Reactivity in Inorganic and Metal-Organic Chemistry, vol. 32, no. 8, pp. 1485-1500, 2002.

[8] A. Gursoy, S. Demirayak, G. Capan, K. Erol, and K. Vural, "Synthesis and preliminary evaluation of new 5-pyrazolinone derivatives as analgesic agents," European Journal of Medicinal Chemistry, vol. 35, no. 3, pp. 359-364, 2000.

[9] Y. Rajendra Prasad, A. Lakshmana Rao, L. Prasoona, K. Murali, and P. Ravi Kumar, "Synthesis and antidepressant activity of some 1,3,5-triphenyl-2-pyrazolines and 3( $2^{\prime \prime}$-hydroxy naphthalen-1" - yl)-1,5-diphenyl-2-pyrazolines," Bioorganic and Medicinal Chemistry Letters, vol. 15, no. 22, pp. 5030-5034, 2005.

[10] Z. Özdemir, H. B. Kandilci, B. Gümüşel, U. Çalış, and A. A. Bilgin, "Synthesis and studies on antidepressant and anticonvulsant activities of some 3-(2-furyl)-pyrazoline derivatives," European Journal of Medicinal Chemistry, vol. 42, no. 3, pp. 373-379, 2007.

[11] Z. Brzozowski, F. Czewski, and M. Gdaniec, "Synthesis, structural characterization and antitumor activity of novel 2,4-diamino-1,3,5-triazine derivatives," European Journal of Medicinal Chemistry, vol. 35, no. 12, pp. 1053-1064, 2000.

[12] G. C. Xu, LI. Zhang, L. Liu, G. F. Liu, and D. Z. Jia, "Syntheses, characterization and crystal structures of mixed-ligand $\mathrm{Cu}(\mathrm{II})$, $\mathrm{Ni}(\mathrm{II})$ and $\mathrm{Mn}(\mathrm{II})$ complexes of N-(1-phenyl-3-methyl-4propenylidene-5-pyrazolone)-salicylidene hydrazide containing ethanol or pyridine as a co-ligand," Polyhedron, vol. 27, no. 1, pp. 12-24, 2008.
[13] Z. Y. Yang, R. D. Yang, F. S. Li, and K. B. Yu, "Crystal structure and antitumor activity of some rare earth metal complexes with Schiff base," Polyhedron, vol. 19, no. 26-27, pp. 25992604, 2000.

[14] F. Marchetti, C. Pettinari, R. Pettinari, A. Cingolani, D. Leonesi, and A. Lorenzotti, "Group 12 metal complexes of tetradentate $\mathrm{N}_{2} \mathrm{O}_{2}$-Schiff-base ligands incorporating pyrazole: synthesis, characterisation and reactivity toward S-donors, $\mathrm{N}$ donors, copper and tin acceptors," Polyhedron, vol. 18, no. 23, pp. 3041-3050, 1999.

[15] G. James, Gappuccino, and N. Sherman, Microbiology, A Laboratory Manual, The Benjamin/Cummings Publishing Company, Calif, USA, 3rd edition, 1992.

[16] P. R. Murray, E. J. Baron, M. A. Pfaller, F. C. Tenover, and R. H. Yolke, Manual of Clinical Microbiology, vol. 6, ASM, Washington, DC, USA, 1995.

[17] B. S. Furniss, A. J. Hannaford, P. W. G. Smith, and A. R. Tatchell, Vogel's Textbook of Practical Organic Chemistry, John Wiley \& Sons, New York, NY, USA, 5th edition, 1989.

[18] B. S. Jensen, "Recent investigation of the tautomerism of pyrazolin-5-ones," Acta Chemica Scandinavica, vol. 13, p. $1668,1959$.

[19] B. Natarajan, S. Mithira, S. Deepa, and P. SambasivaRao, "EPR and optical investigation of $\mathrm{VO}(\mathrm{II})$ in $\mathrm{Zn}\left(\mathrm{C}_{3} \mathrm{H}_{3} \mathrm{O}_{4}\right)_{2}\left(\mathrm{H}_{2} \mathrm{O}\right)_{2}$ single crystals: an interstitial site," Journal of Physics and Chemistry of Solids, vol. 68, no. 10, pp. 1995-2002, 2007.

[20] P. Sambasivarao, "Single-crystal EPR study of Fe(III)-doped magnesium potassium Tutton's salt part 3," Spectrochimica Acta. Part A, vol. 52, no. 9, pp. 1127-1134, 1996.

[21] G. Musie, C. H. Lai, J. H. Reibenspies, L. W. Sumner, and M. Y. Darensbourg, "Pentacoordinate $(\mu$-Oxo)diiron (III) thiolate complexes and dimeric iron(II) precursors," Inorganic Chemistry, vol. 37, no. 16, pp. 4086-4093, 1998.

[22] B. Natarajan, S. Mithira, S. Deepa, and P. Sambasiva Rao, "Single-crystal EPR identification of a low hyperfine value and interstitial position of copper impurity in diaquabis[malonato(1-)- $\left.\kappa^{2} \mathrm{O}, \mathrm{O}^{\prime}\right]$ zinc(II)," Applied Magnetic Resonance, vol. 35, no. 1, pp. 57-71, 2008. 


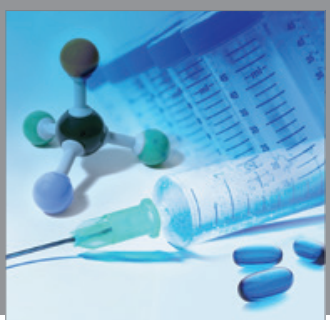

International Journal of

Medicinal Chemistry

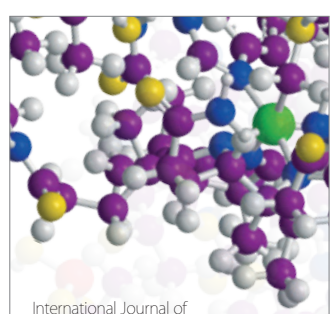

Carbohydrate Chemistry

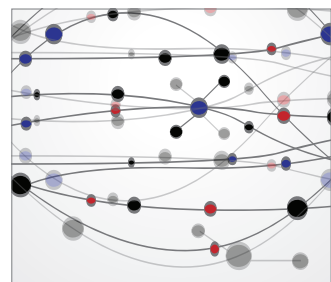

The Scientific World Journal
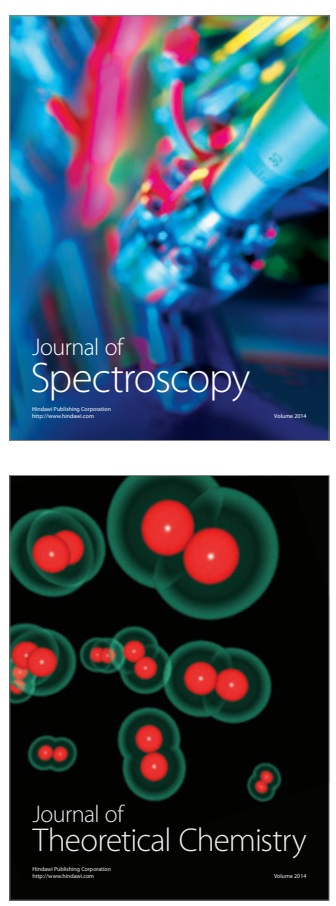
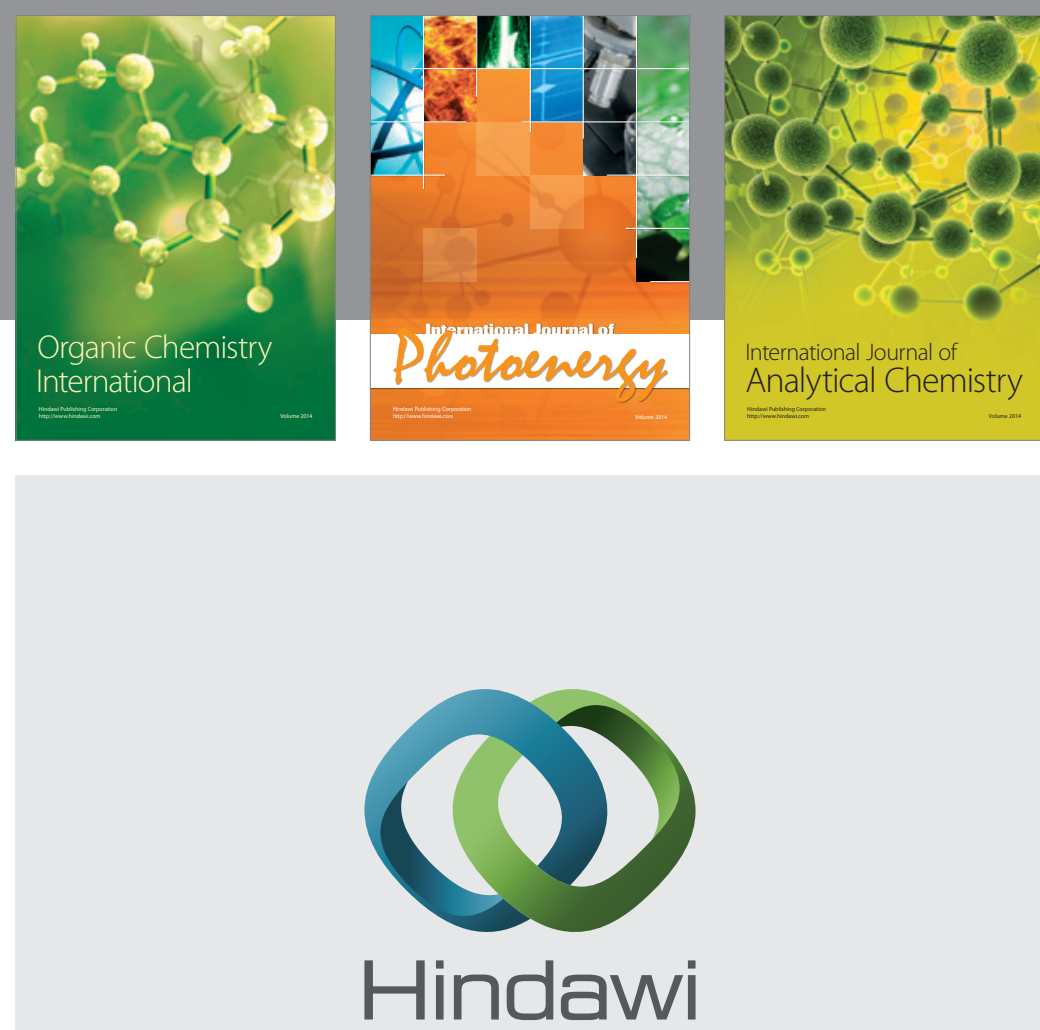

Submit your manuscripts at

http://www.hindawi.com
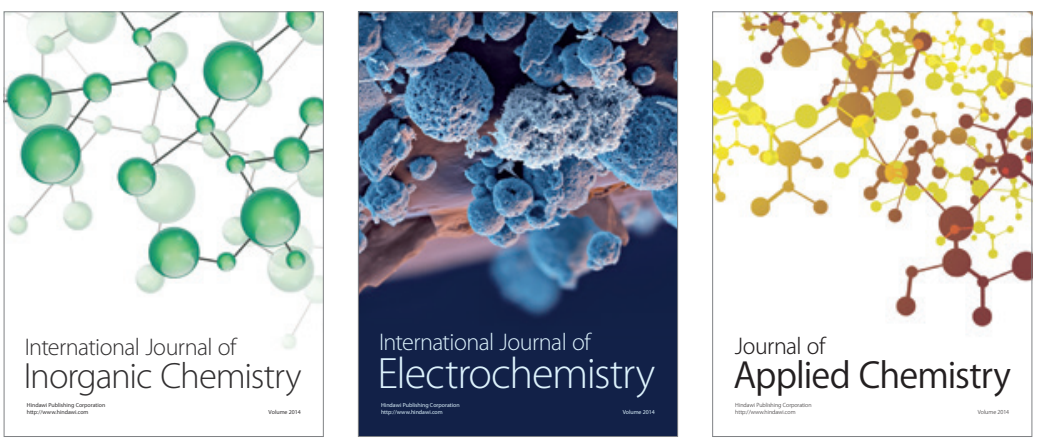

Journal of

Applied Chemistry
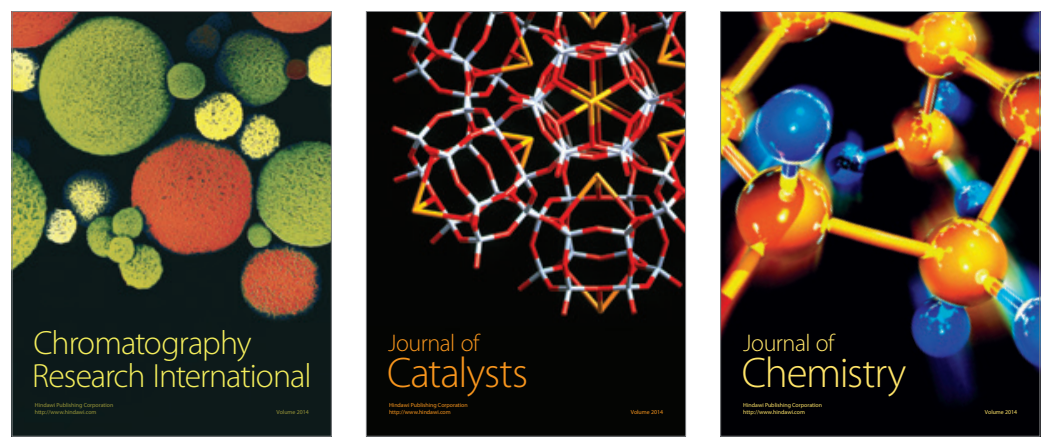
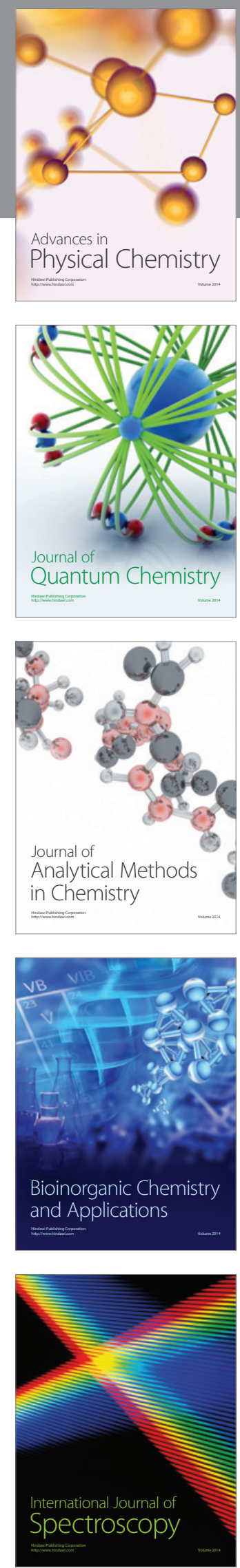